\title{
Magnetic Recyclable Cu/Znfe2o4 for Catalytic Reduction of Nitroarenes And C-N Bond Formation Reactions
}

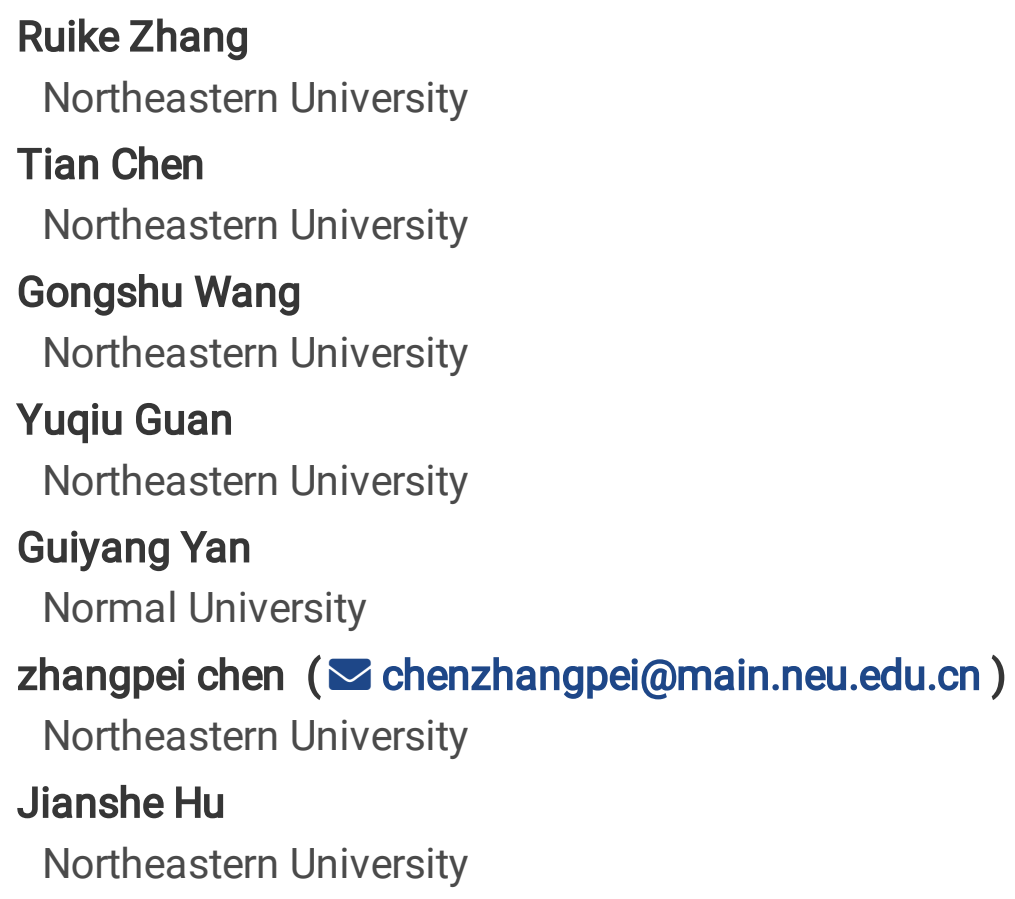

\section{Research Article}

Keywords: zinc ferrite composite materials, magnetic recyclable materials, copper catalysis, heterogeneous catalysis, $\mathrm{C}-\mathrm{N}$ bond formation reactions.

Posted Date: July 12th, 2021

DOI: https://doi.org/10.21203/rs.3.rs-691259/v1

License: (c) (i) This work is licensed under a Creative Commons Attribution 4.0 International License. Read Full License

Version of Record: A version of this preprint was published at Catalysis Letters on January 30th, 2022. See the published version at https://doi.org/10.1007/s10562-021-03906-z. 


\section{Abstract}

A magnetic recyclable $\mathrm{Cu} / \mathrm{ZnFe} \mathrm{O}_{4}$ composite material was successfully prepared with cheap and easyto-obtain raw materials. This obtained copper composite material could be employed as efficient catalyst for both degradation of aromatic nitro compounds and $\mathrm{C}-\mathrm{N}$ bond formation reactions without extra ligands. The aromatic nitro compounds were reduced within 2 min with low catalyst dosage. And high catalytic activity, broad substrate scope and low loading were achieved for Ullmann-type $\mathrm{C}-\mathrm{N}$ bond formation reaction. The morphology of $\mathrm{Cu} / \mathrm{ZnFe}_{2} \mathrm{O}_{4}$ was characterized by Fourier transform infrared spectroscopy (FT-IR), X-ray diffraction (XRD), Thermogravimetric analysis (TGA), Energy disperse spectroscopy (EDS), Transmission electronic microscopy (TEM) and Scanning electron microscopy (SEM). In addition, this environmentally friendly heterogeneous catalyst could simply be recovered via magnetic decantation and used again for six cycles with no considerable loss in activity. This developed magnetic recyclable $\mathrm{Cu} / \mathrm{ZnFe}_{2} \mathrm{O}_{4}$ composite had the characteristics of easy availability, high catalytic performance, good reusability good stability and magnetic recovery properties.

\section{Introduction}

Aromatic nitro compounds which are released from organic or textile industries, have been threatening both environmental safety and human health in recent years. Among them, the p-nitrophenol ( $p$-NP) has been listed as priority toxic pollutants and hazardous wastes by United States Environmental Protection Agency [1]. Therefore, removal or degradation of such toxic compounds from waste water is of great significance. Till date, several methods including electrochemical oxidation [2], adsorption [3], biodegradation [4], and photocatalysis degradation [5] have been developed and applied to this research field. In particular, the catalytic reduction of nitroaromatic compounds to the corresponding amino compounds is considered one of the most efficient method because the generated amino compounds are important intermediates in the preparation of various useful products such as dyes, agricultural and pharmaceutical products [6].

The $\mathrm{N}$-aryl nitrogen-containing heterocycles are valuable compounds that are present in numerous bioactive natural products, synthetic drugs, and materials [7]. Accordingly, the prevalence of these compounds have expedited the exploration of efficient and environmentally benign synthetic methods for their preparation. In this context, the copper-catalyzed Ullmann-type C-N bond formation reactions [8] that enable the coupling of aryl halides with nitrogen-containing compounds representing a straightforward, inexpensive approach to such compounds and have received high priority in synthetic community [9]. However, this copper-catalyzed synthesis usually confronts with some restrictions such as harsh conditions, stoichiometric dosage of copper, limited substrate scope, and reasonable to poor yields [10]. To overcome these drawbacks, researchers have employed several organic ligands and copper salts to facilitate this transformation [11]. In spite of the efficiency of these homogenous catalyst systems, due to the unrecyclable of the metal catalyst and the valuable ligands, together with the separation problems of the products expedited the fabrication of copper based heterogeneous catalysts for the C-N bond formation reaction. Anchoring appropriate ligands and copper to the surface of specially developed 
supports is a viable strategy for the development of heterogeneous catalysts [12]. Several systems have been disclosed based on a series of recyclable supporting materials, such as hydroxyapatites [13], silica based materials [14], carbon nanotube materials [15], metal oxide materials [16], carbon nanotube materials [17], polymers [18] and metal oxide materials [19]. Despite much progress having been achieved in this research field, a great number of problems still remain unsettled, such as the extra synthesis steps for introduction of the ligands, agglomerate problems during the reaction process, reduced activity and reusability caused by the poor stability of the catalyst [20]. Therefore, the development of more efficient and easily available heterogeneous catalysts for the Ullmann-type $\mathrm{C}-\mathrm{N}$ bond formation reactions is still highly desirable.

Zinc ferrite $\left(\mathrm{ZnFe}_{2} \mathrm{O}_{4}\right)$ possesses large saturation magnetization and low coercivity which lead to its huge application prospects as magnetic recyclable materials [21]. Magnetic recyclable catalysts based on zinc ferrite avoiding filtering or centrifugal separation procedures would be a reliable solution for the separation problems in terms of heterogeneous Ullmann-type $\mathrm{C}-\mathrm{N}$ bond formation reactions. However, the fabrication of availably zinc ferrite-supported copper catalyst $\left(\mathrm{Cu} / \mathrm{ZnFe}_{2} \mathrm{O}_{4}\right)$ should settle the following intrinsic obstacles: 1) the difficulty of possessing both high catalytic activity and good magnetic properties because of the fact that the catalytic active copper is prone to be wrapped by the surrounding catalytically inactive magnetic materials; 2 ) the stability of the materials under reaction conditions, such as high temperature, $\mathrm{pH}$, organic corrosion and so on; 3 ) issues associated with the catalytic activities and catalytic efficiency. Considering the importance of developing efficient heterogeneous catalysts for degradation of aromatic nitro compounds and $\mathrm{C}-\mathrm{N}$ bond formation reactions, together with our continuous investigation on the application and development of magnetically recoverable materials [22], herein we wish to report a novel $\mathrm{Cu} / \mathrm{ZnFe}_{2} \mathrm{O}_{4}$ composite material as efficient catalyst for both of the above mention reactions. This developed composite features easy availability, high catalytic performance, and good reusability via a simple magnetic separation method.

\section{Experimental}

\subsection{Synthesis of $\mathrm{Cu} / \mathrm{ZnFe}_{2} \mathrm{O}_{4}$ composite catalyst}

The solution of $\mathrm{Cu}\left(\mathrm{NO}_{2}\right)_{2}(67 \mathrm{mmol})$ dissolved in $100 \mathrm{~mL}$ diethanolamine was heated slowly to $150^{\circ} \mathrm{C}$ and stirred vigorously for $3 \mathrm{~h}$ in nitrogen atmosphere. The color of the mixture turned red as the reaction proceeds. After cool down to room temperature, copper precipitates were obtained by centrifugation. Then, a solution of $\mathrm{FeCl}_{3}(9.5 \mathrm{mmol}, 1.504 \mathrm{~g})$ and $\mathrm{ZnCl}_{2}(4.4 \mathrm{mmol}, 0.600 \mathrm{~g})$ in $100 \mathrm{~mL}$ deionized water was sonicated for $3 \mathrm{~h}$ at room temperature. Then, $\mathrm{NaOH}(3 \mathrm{M}, 30 \mathrm{~mL})$ was added into the mixture. And then the temperature of the ultrasonic water bath was raised to $60^{\circ} \mathrm{C}$ for $1 \mathrm{~h}$, finally magnetic suction out $\mathrm{ZnFe}_{2} \mathrm{O}_{4}$. The obtained $\mathrm{ZnFe}_{2} \mathrm{O}_{4}$ was dispersed in $100 \mathrm{~mL}$ deionized water, and a mixture of the above obtained coppery precipitate in $50 \mathrm{~mL}$ ethanol was added. And the resulting mixture was heated at $80^{\circ} \mathrm{C}$ and agitated for $50 \mathrm{~min}$. The solid precipitate was then separated with a magnetic bar and washed with 
distilled water and anhydrous ethanol. Then the $\mathrm{Cu} / \mathrm{ZnFe}_{2} \mathrm{O}_{4}$ composite was obtained after drying at 160 ${ }^{\circ} \mathrm{C}$ for $2 \mathrm{~h}$.

\section{$2.2 \mathrm{Cu} / \mathrm{ZnFe}{ }_{2} \mathrm{O}_{4}$ catalyzed reduction of p-nitrophenol}

A mixture of p-nitrophenol (2 ml, $400 \mathrm{ppm}), \mathrm{NaBH}_{4}$ and $\mathrm{Cu} / \mathrm{ZnFe}_{2} \mathrm{O}_{4}(3-10 \mathrm{mg})$ was added to a quartz cuvette, and the reaction was monitored with an ultraviolet-visible spectrophotometer. At this time, the system turns from bright yellow to colorless.

\section{$2.3 \mathrm{Cu} / \mathrm{ZnFe}_{2} \mathrm{O}_{4}$ catalyzed $\mathrm{C}-\mathrm{N}$ bond forming reactions}

A mixture of $\mathrm{Cu} / \mathrm{ZnFe}_{2} \mathrm{O}_{4}(100 \mathrm{mg}, 4.8 \mathrm{~mol} \%)$ and $\mathrm{Cs}_{2} \mathrm{CO}_{3}(0.6500 \mathrm{~g}, 2 \mathrm{mmol})$ was added to the resealable test tubes $(25 \mathrm{~mL})$ with Teflon septa. The tube was emptied and filled with nitrogen, then the process was repeated three times. EtOH $(1.0 \mathrm{~mL}), 3 \mathrm{a}(1.5 \mathrm{mmol}, 0.3060 \mathrm{~g})$ and $4 \mathrm{a}(1.0 \mathrm{mmol}, 0.0681 \mathrm{~g})$ were added through a syringe under $\mathrm{N}_{2}$, afterwards sealed the reaction tube. Heated the mixture at $120^{\circ} \mathrm{C}$ for $12 \mathrm{~h}$, and cool down to room temperature. The organic phase was extracted by $\mathrm{CH}_{2} \mathrm{Cl}_{2}$, then dried on anhydrous magnesium sulfate and concentrated by rotary evaporation. Finally, the crude product was purified by column chromatography (ethyl acetate: petroleum ether $=2: 1)$ to afford $5 \mathrm{a}(0.1356 \mathrm{~g}, 94 \%$ yield).

\section{Results And Discussion}

\subsection{Characterization of the $\mathrm{Cu} / \mathrm{ZnFe}_{2} \mathrm{O}_{4}$ catalyst}

The $\mathrm{Cu} / \mathrm{ZnFe}_{2} \mathrm{O}_{4}$ catalyst was synthesized by loading $\mathrm{Cu}$ species on zinc ferrite particles through ultrasound assisted co-precipitation (Supplementary data). The structure of the fabricated zinc ferrite and $\mathrm{Cu} / \mathrm{ZnFe}_{2} \mathrm{O}_{4}$ materials were characterized by FT-IR, XRD, TGA, EDS, TEM and SEM.

As shown in Fig. 1 (a), the absorption peak at $556 \mathrm{~cm}^{-1}$ is attributed to the $\mathrm{Fe}-\mathrm{O}$ vibration from the magnetic basement [23]. The peak near $3440 \mathrm{~cm}^{-1}$ is related to the $\mathrm{O}-\mathrm{H}$ stretching vibration of coordinated the hydroxyl groups and water molecules in the layers. The peak around 1630-1660 and $1383 \mathrm{~cm}^{-1}$ maybe caused by another absorption band corresponding to the water deformation [24]. The absorption peak at $618 \mathrm{~cm}^{-1}$ indicated the existence of copper nanoparticles [25]. The TGA curves of $\mathrm{Cu} / \mathrm{ZnFe}_{2} \mathrm{O}_{4}$ and $\mathrm{ZnFe}_{2} \mathrm{O}_{4}$ were shown in Fig. 1 (b). The $\mathrm{Cu} / \mathrm{ZnFe}_{2} \mathrm{O}_{4}$ and $\mathrm{ZnFe}_{2} \mathrm{O}_{4}$ showed a mass loss of $7 \%$, which was attributed to the loss of adsorbed water on the sample surface. Furthermore, the mass loss of $\mathrm{Cu} / \mathrm{ZnFe}_{2} \mathrm{O}_{4}$ and $\mathrm{ZnFe}_{2} \mathrm{O}_{4}$ was $2 \%$, which was due to the loss of crystalline water bound within the sample. The mass of $\mathrm{Cu} / \mathrm{ZnFe}_{2} \mathrm{O}_{4}$ catalyst does not decreased significantly at $700{ }^{\circ} \mathrm{C}$, which indicates that the $\mathrm{Cu} / \mathrm{ZnFe}_{2} \mathrm{O}_{4}$ catalyst had good thermal stability. The Fig. 1 (c) showed the XRD patterns of $\mathrm{Cu} / \mathrm{ZnFe}_{2} \mathrm{O}_{4}, \mathrm{Cu}$ (PDF\#03-1015) and $\mathrm{ZnFe}_{2} \mathrm{O}_{4}$ (PDF\#01-1108). The position and relative intensity of the position and relative intensity of the peaks in the $\mathrm{Cu} / \mathrm{ZnFe}_{2} \mathrm{O}_{4}$ of XRD pattern were consistent with the 
standard XRD pattern of $\mathrm{ZnFe}_{2} \mathrm{O}_{4}$ and $\mathrm{Cu}$, indicating that the crystal structure of $\mathrm{ZnFe}_{2} \mathrm{O}_{4}$ was maintained during $\mathrm{Cu}$ loading processes. As shown in Fig. 1 (d) the elemental composition was determined by EDS analysis and the results indicated the existence of $\mathrm{O}, \mathrm{Cu}, \mathrm{Zn}$ and Fe elements and further confirmed the structure of $\mathrm{Cu} / \mathrm{ZnFe}_{2} \mathrm{O}_{4}$. The SEM and TEM images of the obtained catalysts were showed in Fig. 1 (e) (f) (g) (h). As shown, $\mathrm{Cu} / \mathrm{ZnFe}_{2} \mathrm{O}_{4}$ and $\mathrm{ZnFe}_{2} \mathrm{O}_{4}$ were still irregular shape and nearly uniform size. The surface of $\mathrm{ZnFe}_{2} \mathrm{O}_{4}$ is changed after the introduction of $\mathrm{Cu}$ nanoparticles, and needlelike $\mathrm{Cu}$ single crystals are loaded on the original smooth surface.

\subsection{Degradation of aromatic nitro compounds with $\mathrm{Cu} / \mathrm{ZnFe}_{2} \mathrm{O}_{4}$}

After investigation of the morphology of $\mathrm{Cu} / \mathrm{ZnFe}_{2} \mathrm{O}_{4}$, we continue to study the catalytic performance of $\mathrm{Cu} / \mathrm{ZnFe}_{2} \mathrm{O}_{4}$. The catalytic activity of $\mathrm{Cu} / \mathrm{ZnFe}_{2} \mathrm{O}_{4}$ in the reduction process of $\mathrm{p}$-nitrophenol to $\mathrm{p}$ aminophenol was investigated with $\mathrm{NaBH}_{4}$ as the reducing agent. Add p-nitrophenol (2 ml, $\left.400 \mathrm{ppm}\right)$, $\mathrm{NaBH}_{4}$ and $\mathrm{Cu} / \mathrm{ZnFe}_{2} \mathrm{O}_{4}(3 \mathrm{mg}, 5 \mathrm{mg}, 7 \mathrm{mg}, 10 \mathrm{mg})$ to the flask, and measure the data with an ultravioletvisible spectrophotometer with a wavelength of $200-600 \mathrm{~nm}$. The decrease in peak intensity at $400 \mathrm{~nm}$ is due to the reduction of p-nitrophenol. At this time, the stability of the peak intensity also indicates the proceeding of the reaction. Fig. 2 (a) depicted the UV spectra of the reduction of p-nitrophenol in terms of different reaction time. Fig. 2 (b) and (c) showed the kinetic experiments of the reduction reactions. As shown in formula (1), $C_{t}$ is concentration of $p$-nitrophenol with the passage of time, and $C_{0}$ is concentration of $p$-acylphenol at the beginning of the reaction.

$\operatorname{Ln}\left(C_{t} / C_{0}\right)=k t$

When the catalyst dosage is increased from $3 \mathrm{mg}$ to $10 \mathrm{mg}$, the $\mathrm{k}$ value increased from $1.31 \times 10^{-2} / \mathrm{s}$ to $4.02 \times 10^{-2} / \mathrm{s}$, the time required for the complete reduction of $\mathrm{p}$-nitrophenol also decreased from $330 \mathrm{~s}$ to $120 \mathrm{~s}$. As the concentration increases, the reaction rate also increases. The rate of reaction depends on concentration of $p$-nitrophenol, which conforms to the characteristics of a quasi-first order reaction. These studies demonstrated that in the reduction of p-nitrophenol, the $\mathrm{Cu} / \mathrm{ZnFe}_{2} \mathrm{O}_{4}$ exhibited good catalytic activity.

Subsequently, in order to further explore the application of this catalyst in the reduction of aromatic nitro compounds, an array of substrate scope experiments was carried out under the optimum reaction conditions. As shown in Fig. 2 (d), all of the investigated nitro aromatic compounds are reduced to the corresponding amino compounds with high yields (Supplementary data). A series of functional groups were well tolerated including halogen, hydroxyl, carboxyl, alkoxy groups. Notably, both of the two nitro groups of 1,3-dinitrobenzene substrate could be reduced to amino groups in this transformation in $98 \%$ yield.

\section{3 $\mathrm{Cu} / \mathrm{ZnFe}_{2} \mathrm{O}_{4}$ catalyzed $\mathrm{C}-\mathrm{N}$ bond formation reactions}

\subsubsection{Optimization of $\mathrm{C}-\mathrm{N}$ bond formation reaction conditions}


To further estimate the application possibility of $\mathrm{Cu} / \mathrm{ZnFe}_{2} \mathrm{O}_{4}$ in catalysis, the $\mathrm{C}-\mathrm{N}$ bond formation reactions were further investigated with iodobenzene ( $3 a$ ) and imidazole (4a) as the model substrates. Table 1 shows the reaction condition optimization studies. Generally, the nitrogen-based ligands play significant roles in the interaction with metal centers and affect the efficiency of the catalyst system in the $\mathrm{C}-\mathrm{N}$ bond formation reactions [26]. Therefore, we firstly screened some commercially available ligands on the reactivity, including 1,10-phenanthroline, p-toluenethiol, thioanisole, and proline (entries 1-4). To our delight, we found that the reaction proceeded well without any extra ligand and the yield reached $94 \%$ with $\mathrm{Cs}_{2} \mathrm{CO}_{3}$ as the base in ethanol at $120^{\circ} \mathrm{C}$ (entry 5). To our disappointment, further screening the base failed to elevate the reaction yield, including $\mathrm{K}_{2} \mathrm{CO}_{3}, \mathrm{NaOH}$, and $\mathrm{KOH}$ (entries 6-8). Increasing the catalyst dosage (entry 9), elevating the reaction temperature (entry 10 ), and prolonging the reaction time (entry 11 ) also failed to increase the yield. What's more, decreasing the temperature (entry 12) or shortening the reaction time (entry 13 ) the reactivity deteriorated dramatically. In addition, altering the ratio of $\mathbf{3 a}$ and $\mathbf{4 a}$ had almost no influence on the reactivity (entries 14-15). Hence the optimal conditions for this reaction were as follows: $100 \mathrm{mg}$ of $\mathrm{Cu} / \mathrm{ZnFe}_{2} \mathrm{O}_{4}, 120^{\circ} \mathrm{C}, 1.5$ equiv. iodobenzene and 2.0 equiv. of $\mathrm{Cs}_{2} \mathrm{CO}_{3}$ were added to ethanol for $12 \mathrm{~h}$.

\subsubsection{Substrate scope and recyclability investigations}

Under the optimal conditions, the substrate scope of aryl halides and nucleophilic reagents were investigated and the results were shown in Table 2. In general, various aryl halides were transformed into the coupling products with $50-94 \%$ yields. The functional groups including methyl, methoxy, nitro, cyanide, bromine and trifluoromethyl were tolerated in this reaction. Then the steric effects were investigated via the exploration of substrates bearing methyl group at different position of aryl iodides (entries 2-4). Results demonstrated that the reaction proceeded mildly and delivered the products with high yields. Subsequently, the electronic effects of p-phenyl substituents were conducted (entries 5-9). Substrates bearing both electron-donating groups and electron-withdrawing groups could be converted to the products in $83-89 \%$ yield. It is noteworthy that other nucleophiles such as (benzo)imidazoles, benzotriazoles, pyrazols, and pyrroles were also tolerated in this reaction resulting in the corresponding products with high yields (entries 10-15). In addition, transformations with arylamines and cyclic amines, such as 1-phenylpiperazine, morpholine, and piperidine were also viable and furnished the products in 60$94 \%$ yields (entries 14-20). In order to further exploration of the substrate scope, several aryl bromides were also subjected to this transformation and all of the reactions were happened stably in $50-74 \%$ yields (entries 21-27). Disappointingly, reaction with aryl chloride as the coupling agent generated the product with only $10 \%$ of yield (entry 28 ).

Since one of the key properties of our catalysts is the magnetic response, the recovery and reuse of catalysts were worth focusing on. We are pleased that the catalysts could be quickly and easily recovered from the product via an external magnetic field. The results show that the catalyst could be recovered quickly and easily in the reaction system and used continuously for 6 times without obvious loss of activity (Figure 3). 


\section{Conclusions}

To sum up, a magnetic recoverable $\mathrm{Cu} / \mathrm{ZnFe}_{2} \mathrm{O}_{4}$ composite material was successfully prepared and well characterized. This copper composite material performed well in the reduction of nitroaromatics to amino aromatics with sodium borohydride as the reductant. For the Ullmann-type $\mathrm{C}-\mathrm{N}$ bond formation reactions, $\mathrm{Cu} / \mathrm{ZnFe}_{2} \mathrm{O}_{4}$ could also exhibit good catalytic activity and delivering the corresponding $\mathrm{N}$-aryl nitrogencontaining heterocycles products with good to excellent yields. What's more, this heterogeneous catalyst could be easily separated and reused for several consecutive times with a magnetic bar without significant loss of their catalytic efficiency. Further investigations on applications of this magnetic recyclable copper composite material are underway in our laboratory.

\section{Declarations}

\section{Acknowledgments}

This work was supported by the Fundamental Research Funds for the Central Universities (N2005004, N1 80705004), and Fujian Province University Key Laboratory of Green Energy and Environment Catalysis, Ningde Normal University. The article has no conflict of interest. The data in this article is real and usable and agree to published.

\section{References}

1. H. Pan, Y. Peng, X. Lu, J. He, L. He, C. Wang, F. Yue, H. Zhang, D. Zhou, Q. Xia, Well-constructed $\mathrm{Ni@CN}$ material derived from di-ligands Ni-MOF to catalyze mild hydrogenation of nitroarenes. Mol. Catal. 485, 110838 (2020). https://doi.org/10.1016/j.mcat.2020.110838

2. S.A. Ture, V.B. Patil, C.V. Yelamaggad, R. Martínez-Máñez, V. Abbaraju, Understanding of mechanistic perspective in sensing of energetic nitro compounds through spectroscopic and electrochemical studies. J. Appl. Polym. Sci. 138, 50776 (2021). https://doi.org/10.1002/app.50776

3. M. Nasrollahzadeh, M. Sajjadi, S. Iravani, R.S. Varma, Green-synthesized nanocatalysts and nanomaterials for water treatment: Current challenges and future perspectives. J. Hazard. Mater. 401, 123401 (2021). https://doi.org/10.1016/j.jhazmat.2020.123401

4. Y. Wang, Y. Hou, Q. Wang, Y. Wang, The elucidation of the biodegradation of nitrobenzene and $\mathrm{p}-$ nitrophenol of nitroreductase from Antarctic psychrophile Psychrobacter sp. ANT206 under low temperature. J. Hazard. Mater. 413, 125377 (2021). https://doi.org/10.1016/j.jhazmat.2021.125377

5. X. Pu, B. Zhang, Y. Su, Heterogeneous Photocatalysis in Microreactors for Efficient Reduction of Nitrobenzene to Aniline: Mechanisms and Energy Efficiency. Chem Eng Technol. 42, 2146-2153 (2019). https://doi.org/10.1002/ceat.201800735

6. R. Hosseinzadeh, N. Aghili, M. Tajbakhsh, SBA-15 Immobilized Phenanthroline-Copper(I) Complex as a Recyclable Efficient Catalyst for $\mathrm{N}$-Arylation of Amides and $\mathrm{N}-\mathrm{H}$ Heterocycles with Aryl Halides. Catal Lett. 146, 193-203 (2015). https://10.1007/s10562-015-1622-4 
7. R. Xiao, H. Zhao, M. Cai, MCM-41-immobilized bidentate nitrogen copper(I) complex: a highly efficient and recyclable catalyst for Buchwald N-arylation of indoles. Tetrahedron Lett. 69, 5444-5450 (2013). https://doi.org/10.1016/j.tet.2013.04.106

8. S. Hemmati, S. Ahany Kamangar, M. Yousefi, M. Hashemi Salehi, M. Hekmati, Cu(I)-anchored polyvinyl alcohol coated-magnetic nanoparticles as heterogeneous nanocatalyst in Ullmann-type CN coupling reactions. Appl. Organomet. Chem. 34, e5611 (2020). https://doi.org/10.1002/aoc.5611

9. A.R. Sardarian, M. Kazemnejadi, M. Esmaeilpour, Functionalization of superparamagnetic Fe304@SiO2 nanoparticles with a Cu(II) binuclear Schiff base complex as an efficient and reusable nanomagnetic catalyst for $\mathrm{N}$-arylation of a-amino acids and nitrogen-containing heterocycles with aryl halides. Appl. Organomet. Chem. 35, e6051 (2021). https://doi.org/10.1002/aoc.6051

10. S.H. Alelaiwi, J.R. McKee, One-Pot Synthesis of Aminated Benzo-Fused Heterocycles and NSubstituted Dibenzothiophenes via Copper-Catalyzed Ullmann Type Reaction. ACS Omega. 6, 60096016 (2021). https://doi.org/10.1021/acsomega.1c00414

11. X. Zhao, Y. She, K. Fang, G. Li, CuCl-Catalyzed Ullmann-Type C-N Cross-Coupling Reaction of Carbazoles and 2-Bromopyridine Derivatives. J. Org. Chem. 82, 1024-1033 (2017). https://doi.org/10.1021/acs.joc.6b02595

12. J.B. Fathima, A. Pugazhendhi, M. Oves, R. Venis, Synthesis of eco-friendly copper nanoparticles for augmentation of catalytic degradation of organic dyes. J. Mol. Liq. 260, 1-8 (2018). https://doi.org/10.1016/j.molliq.2018.03.033

13. S. Hemmati, A. Naderi, M. Ghadermazi, H. Veisi, SiO2-functionalized melamine-pyridine groupsupported $\mathrm{Cu}(\mathrm{OAc}) 2$ as an efficient heterogeneous and recyclable nanocatalyst for the $\mathrm{N}$-arylation of amines through Ullmann coupling reactions. C. R. Chim. 21, 659-668 (2018). https://doi.org/10.1016/j.crci.2018.03.002

14. E. Akhavan, S. Hemmati, M. Hekmati, H. Veisi, CuCl heterogenized on metformine-modified multi walled carbon nanotubes as a recyclable nanocatalyst for Ullmann-type $\mathrm{C}-\mathrm{O}$ and $\mathrm{C}-\mathrm{N}$ coupling reactions. New J Chem. 42, 2782-2789 (2018). https://doi.org/10.1039/C7NJ03240D

15. H. Veisi, Y. Metghalchi, M. Hekmati, S. Samadzadeh, Cul heterogenized on thiosemicarbazide modified-multi walled carbon nanotubes (thiosemicarbazide-MWCNTs-Cul): Novel heterogeneous and reusable nanocatalyst in the C-N Ullmann coupling reactions, Appl. Organomet. Chem. 31 (2017). https://doi.org/10.1002/aoc.3676

16. C. Bodhak, A. Kundu, A. Pramanik, An efficient and recyclable chitosan supported copper(II) heterogeneous catalyst for $\mathrm{C}-\mathrm{N}$ cross coupling between aryl halides and aliphatic diamines. Tetrahedron Lett. 56, 419-424 (2015). https://doi.org/10.1016/j.tetlet.2014.11.120

17. S. Anuradha, D.D. Kumari, Pathak, Synthesis and development of Chitosan anchored copper(II) Schiff base complexes as heterogeneous catalysts for $\mathrm{N}$-arylation of amines. Tetrahedron Lett. 56, 41354142 (2015). https://doi.org/10.1016/j.tetlet.2015.05.049

18. A. Bukowska, W. Bukowski, K. Bester, K. Hus, Polymer supported copper(II) amine-imine complexes in the C-N and A ${ }^{3}$ coupling reactions, Appl Organome Chem. 31 (2017). 
https://doi.org/10.1002/aoc.3847

19. X. Ge, X. Chen, C. Qian, S. Zhou, Efficient Ullmann C-N coupling catalyzed by a recoverable oligosesupported copper complex. RSC Advances. 6, 58898-58906 (2016). https://doi.org/10.1039/C6RA13536F

20. M. Nasrollahzadeh, M. Sajjadi, M. Shokouhimehr, R.S. Varma, Recent developments in palladium (nano)catalysts supported on polymers for selective and sustainable oxidation processes. Coord Chem Rev. 397, 54-75 (2019). https://doi.org/10.1016/j.ccr.2019.06.010

21. R. Shu, G. Zhang, J. Zhang, X. Wang, M. Wang, Y. Gan, J. Shi, J. He, Synthesis and high-performance microwave absorption of reduced graphene oxide/zinc ferrite hybrid nanocomposite. Maters Lett. 215, 229-232 (2018). https://doi.org/10.1016/j.matlet.2017.12.108

22. G. Wang, Z. Ding, L. Meng, G. Yan, Z. Chen, J. Hu, Magnetically recoverable 2-(aminomethyl)phenolsmodified nanoparticles as a catalyst for Knoevenagel condensation and carrier for palladium to catalytic Suzuki coupling reactions. Appl. Organomet. Chem. 34, e5907 (2020). https://doi.org/10.1002/aoc.5907

23. M.A. Ghasemzadeh, B.M.H. Abdollahi, M. Babaei, Fe3O4@SiO2-NH2 core-shell nanocomposite as an efficient and green catalyst for the multi-component synthesis of highly substituted chromeno[2,3b] pyridines in aqueous ethanol media. Green Chem. Lett. Rev. 8, 40 (2015). https://doi.org/10.1080/17518253.2015.1107139

24. F. Pazoki, J.A. Mehraban, M. Shamsayei, B. Bakhshi, R. Esfandiarpour, M.K. Miraki, A. Heydari, AzaMichael Addition of 5-Substituted Tetrazole Catalysed By a Novel Nanoparticle Solid Base Catalyst Involving a Layered Zinc Hydroxide Supported on a Ferrite Core. ChemistrySelect. 4, 2568-2575 (2019). https://doi.org/10.1002/slct.201804070

25. Y. Zhang, Y.U. Lili, Y. Yang, N. Jia, A non enzymatic glucose sensor based on electrodepositing Cu/ graphene nanocomposite film modified electrode. Journal of Shanghai Normal University 42, 37-43 (2013). https://doi.org/10.3969/J.ISSN.1000-5137.2013.01.007

26. P.P. Cellier, J.-F. Spindler, M. Taillefer, H.-J. Cristau, Pd/C-catalyzed room-temperature hydrodehalogenation of aryl halides with hydrazine hydrochloride. Tetrahedron Lett. 44, 7191-7195 (2003). https://doi.org/10.1016/S0040-4039(03)01789-1

\section{Tables}

Due to technical limitations, Tables are only available as a download in the Supplemental Files section.

\section{Figures}



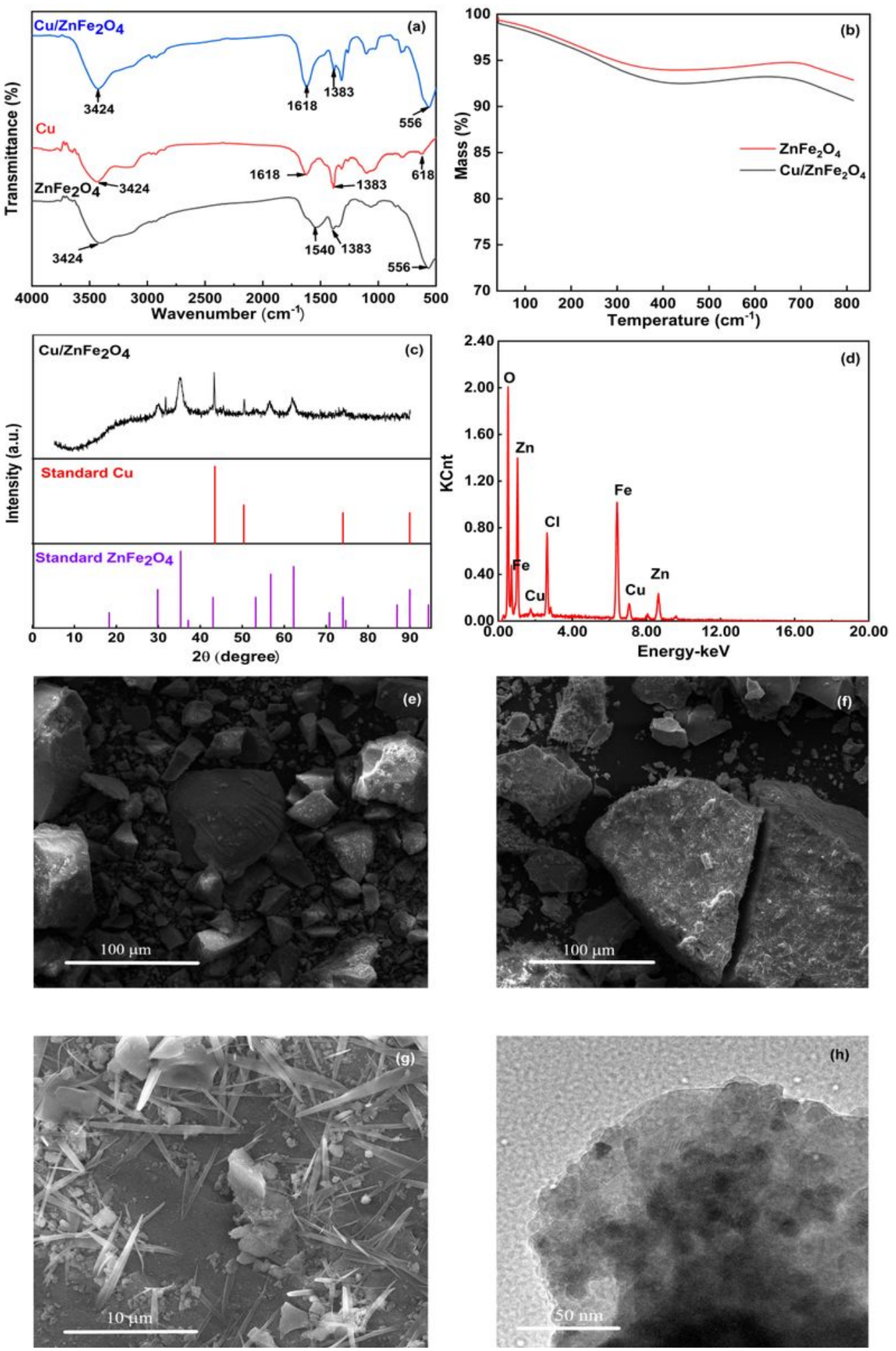

\section{Figure 1}

(a) FT-IR spectra of $\mathrm{Cu} / \mathrm{ZnFe204}$, $\mathrm{Cu}$ and $\mathrm{ZnFe204}$; (b) TGA curves of $\mathrm{Cu} / \mathrm{ZnFe2O} 4$ and ZnFe204; (c) XRD patterns of Cu/ZnFe2O4; (d) EDS image of Cu/ZnFe2O4; (e) SEM image of ZnFe2O4; (f) SEM image of $\mathrm{Cu} / \mathrm{ZnFe2O4;} \mathrm{(g)} \mathrm{SEM} \mathrm{image} \mathrm{of} \mathrm{Cu/ZnFe2O4;} \mathrm{(h)} \mathrm{TEM} \mathrm{image} \mathrm{of} \mathrm{Cu/ZnFe2O4.}$ 

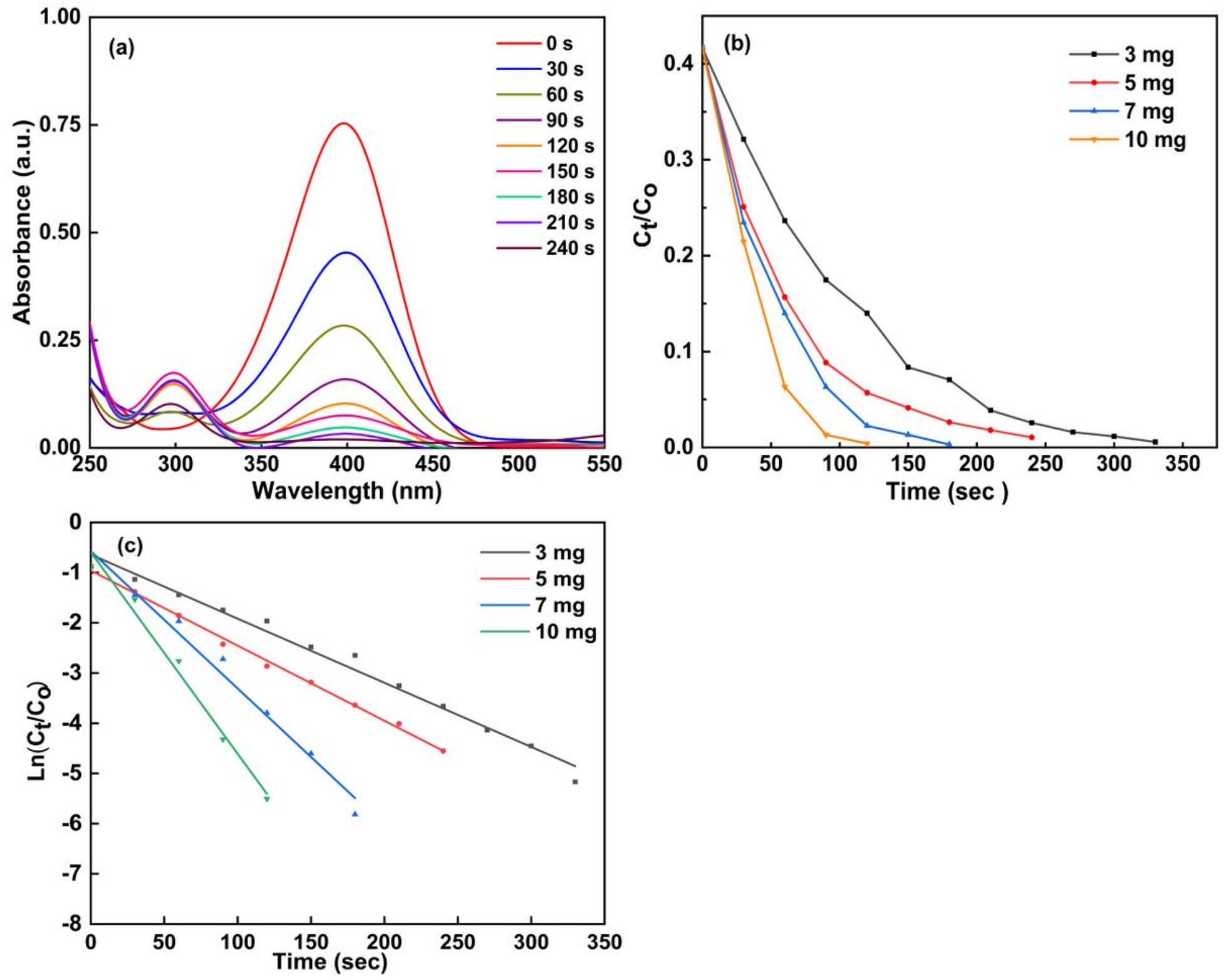

Figure 2

(a) UV spectra of and kinetic curves of the reduction of 4-NP to 4-AP. (b) influence of catalyst loading and reaction time on the reactivity. (c) kinetic curve of the reduction of 4-NP to 4-AP. (d) Catalytic reduction of other nitroarenes with $\mathrm{Cu} / \mathrm{ZnFe} 2 \mathrm{O} 4$ under optimized conditions. 

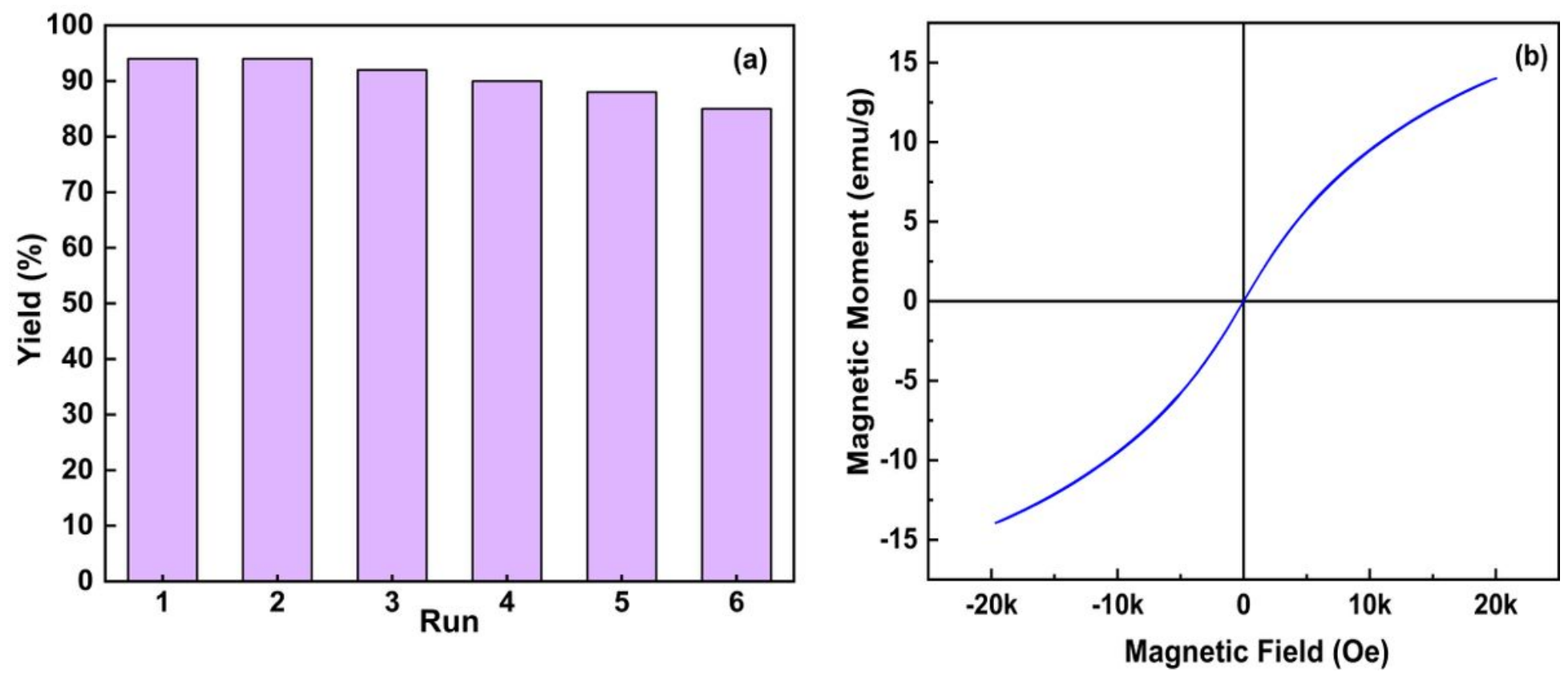

Figure 3

(a) Recyclability of the Cu/ZnFe2O4 catalyst. (b) VSM study of Cu/ZnFe2O4.

\section{Supplementary Files}

This is a list of supplementary files associated with this preprint. Click to download.

- Table1and2.docx

- renamedef1bf.docx 